Beitrag zur Lehre von der Constitution der Lösungen. Ann. Phys. u. Chem. 52: 166-190.

Nifisex, N. 1924. Studies on the transmission of stimuli in the coleoptile of Avena. Dansk Bot. Ar. 4: 1-45. önols, L. W. 1910. Die freie Diffusion der Nichtelektrolyte. I. Über hydrodiffusion einiger optisch aktiven Substanzen. Zeitschr. Physiol. Chem. 70: 378407.

Skubert, E. 1925. Über Wachstumsregulatoren in der Koleoptile von Avena. Zeitschr. Bot. 17: 49-88.
Stark, P. 1921. Studien über traumatotrope und haptotrope Reizleitungsvorgänge mit besonderer Berücksichtigung der Reizübertragung auf fremde Arten und Gattungen. Jahrb. Wiss. Bot. 60: 67-134.

Steray, J. 1879. Über die Diffusion der Flüssigkeiten. Sitzungsber. Wiener Akad. Math.-Naturw. Cl. 79 (2) : 161-214,

Stewart, W. S., W. Bergren, and C. E. Redpmany. 1939. A plant growth inhibitor. Science $89: 185-186$.

Went, F. W. 1928. Wuchsstoff und Wachstum. Rec. Trav. Bot. Néerl. 25: 1-116.

\title{
THE CAUSE OF NATURAL PARTHENOCARPY ${ }^{1}$
}

\section{Felix G. Gustafson}

That IT is possible to produce parthenocarpic fruits artificially by treating the pistil of a flower in the bud stage with growth promoting substances or auxins, as they will be called in this paper (Went and Thimann, 1937), has now been shown by several investigators (Gustafson, 1936; Hagemann, 1937; Gardner and Marth, 1937). From this fact and the fact that auxin is known to be widely distributed in the higher plants we may assume that auxin naturally plays a part in the growth of a fruit. If so, where does it come from?

Suggestions have been made that the auxin comes from the pollen or the developing seeds (Dollfus, 1936; Gustafson, 1937, 1938a). Laibach (1932) and Thimann (1934) have shown that pollen contains auxin. As to the latter suggestion, it will suffice to point out that there are fruits without seeds such as the orange, lemon, grapefruit, banana, grape, cucumber, and others. Recently Gustafson $(1938 \mathrm{a}, 1938 \mathrm{~b})$ proposed the hypothesis that the reason some plants produce fruits parthenocarpically is that the ovaries of these plants contain, in the flower bud stage, enough auxin to cause them to commence growing without fertilization, while the ovaries of other plants commence growing only after pollination and fertilization have augmented the auxin supply already in them. We may then think of the usual fruit growth as being initiated by pollination and fertilization, which brings into the ovary a sufficient quantity of auxin from the pollen grains and pollen tubes to start the enlargement of the ovary (Gustafson, 1937), and continued by the additional auxin produced by the developing embryos and seeds, which diffuses into the ovary

1 Received for publication December 7, 1938.

Paper from the Department of Botany of the University of Michigan, No. 681 .

The writer wishes to express his thanks and appreciation to F. W. Went, E. G. Anderson, J. Van Overbeek, and $\mathrm{Wm}$. S. Stewart of the California Institute of Technology, to J. W. Lesley, H. B. Frost, and I. J. Condit of the Citrus Experiment Station, Riverside, California, to C. S. Pomeroy of the U. S. Department of Agriculture, Riverside, and to W. E. Lammerts, Ontario, California, for various aids extended during the course of this investigation and to the Directors of the Horace $\mathrm{H}$. Rackham Trust Fund of the University of Michigan for financial aid. to supply what is needed. Contrasted with this is the formation of a fruit from an ovary which contains enough initial auxin within itself to start enlargement without any additional being derived from pollination and fertilization, the resulting young fruit either producing its own auxin or obtaining it from the leaves. The fruits produced in this way are parthenocarpic.

The purpose of this investigation was to compare the auxin concentration in the ovaries, at flower bud stage, from plants that produce fruits parthenocarpically and from plants that require fertilization.

Procedure.-The work here reported was done at the William G. Kerckhoff Laboratories at the California Institute of Technology. The citrus material was obtained either from the Citrus $\mathrm{Ex}$ periment Station at Riverside or from the Armstrong Nurseries at Ontario, California. All the grape material came from the Armstrong Nurseries. The growth hormone content was determined by the Avena method, the technique of which has been discussed in detail by Went and Thimann (1937).

The auxin was extracted with freshly distilled ether according to Van Overbeek's (1938) modification of other methods. The dried residue was thoroughly mixed with a small amount (usually 0.4 to $0.8 \mathrm{cc}$.) of 1.5 per cent agar, and after standing 90 minutes was poured into a nickel plated brass mold $1.5 \times 8.0 \times 10.5 \mathrm{~mm}$. in size. After the agar had been cut level with the surface of the mold, the large block was cut into 12 equal pieces. The material was now ready for the test. Great care was taken to have freshly prepared extracts. Usually the extract was prepared the same day that it was used, but if it could not be used the same day that it was made, it was always stored in a ref rigerator in dried condition. The extraction was always carried out in the dark and usually, though not always, at a low temperature.

Control experiments in which Avena plants were treated with a known concentration of indole acetic acid (usually 21.5 gammas per liter) were run with every experiment. By this means the sensitivity of the test plants was determined for each experiment, which was very important because there was considerable variation day by day, and the auxin 
TABLE 1. Auxin content in the ovaries of unopened flowers and in young fruits of oranges and lemons.-The auxin concentration is denoted in terms of indole acetic acid equivalents, and the figures are gammas per kilogram of fresh material.

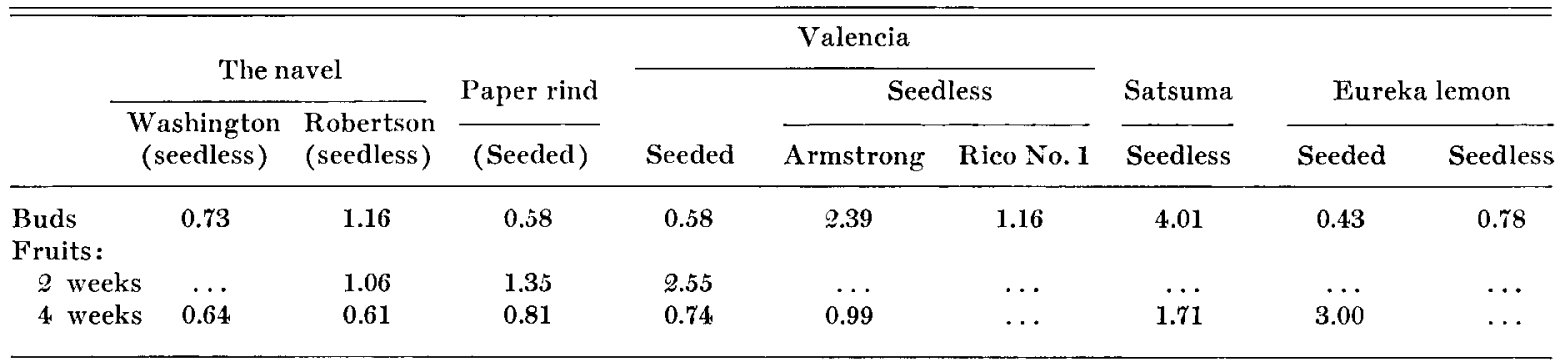

concentration in a plant can be calculated in terms of indole acetic acid (see Van Overbeek) rather than in terms of some of the many units which have been employed by different investigators.

A few experiments were performed in which the plant material was placed on the agar blocks as in Went's original experiments. In most instances such blocks when placed on Avena coleoptiles caused no curvatures. It had been hoped that this method could be used, but since so few plants gave any results it was abandoned for the extraction method.

Results and discussion.-It very soon became obvious that one could not profitably compare unrelated species with one another because the difference in the auxin content in the vegetative parts of different species varies greatly. Therefore it was necessary to obtain varieties of the same species that were parthenocarpic and non-parthenocarpic. Fortunately, the nearby Citrus Experiment Station at Riverside had a great variety of oranges, some producing seeds and others not. Through the courtesy of Dr. H. B. Frost an abundance of flower buds and young fruits were obtained from several varieties that were selected after a careful investigation of relationships. Two varieties of oranges were also obtained from the Armstrong Nurseries at Ontario through the courtesy of Dr. W. E. Lammert, and the Seedless Valencia Rico No. 1 was obtained from Mr. C. S. Pomeroy of the $U$. S. Department of Agriculture at Riverside.

The varieties finally used were the seedless Navel varieties Washington and Robertson, the latter being a sport of the former; Paper rind, a seeded form; three varieties of Valencia - the ordinary seeded variety, a seedless sport of the seeded variety called Armstrong, and a seedless form called Rico No. 1, which was introduced from Porto Rico and may not be related to the Valencia, though it looks like it. These six varieties are very closely related to one another. Since all belong to Citrus sinensis, they can properly be compared. Satsuma, a seedless variety of $C$. nobilis, was also used, but it cannot be compared directly with the others. After it was discovered that there existed a tree of seedless lemons (Citrus Limonia) in Riverside, Eureka lemon was also used.

It must be stated that authorities on the subject are not agreed as to whether pollination is or is not necessary for the fruit production in oranges. Evidence points towards the lack of necessity for

TABLE 2. The amount of fresh material used of each variety, the quantity of 1.5 per cent agar with which the dry residue zoas mixed, the mean curvature of 24 Avena coleoptiles treated with this agar, the mean curvature of 24 control Avena coleoptiles treated with indole acetic acid (21.5 gammas per $\mathrm{kg}$.), and the concentration of auxin in terms of indole acetic acid equivalents in gammas per kilogram fresh material as calculated by the formula $c \times s \times v / w$, (Van Overbeek, 1938), where $c$ is the curvature of the experimental plants, $s$ the sensitivity of the Avena plants or the number of gammas of indole acetic acid required to produce one degree of curvature, $v$ the volume of agar with which the residue was mixed, and w the fresh weight of the material used.

\begin{tabular}{|c|c|c|c|c|c|c|}
\hline \multirow[b]{3}{*}{ Notation } & & & \multicolumn{2}{|c|}{ Oranges } & \multirow{3}{*}{$\begin{array}{l}\text { Valencia } \\
\text { (seeded) }\end{array}$} & \multirow{3}{*}{$\begin{array}{c}\text { Indole } \\
\text { acetic acid } \\
(21.5 \gamma)\end{array}$} \\
\hline & \multicolumn{2}{|c|}{ Eureka lemon } & \multirow{2}{*}{$\begin{array}{c}\text { Washington } \\
\text { navel } \\
\text { (seedless) }\end{array}$} & \multirow{2}{*}{$\begin{array}{l}\text { Paper } \\
\text { rind } \\
\text { (seeded) }\end{array}$} & & \\
\hline & Seeded & Seedless & & & & \\
\hline Weight in gm. ......... & 18.80 & 18.45 & 32.10 & 19.21 & 18.15 & $\ldots$ \\
\hline Agar cc. $\ldots \ldots \ldots \ldots \ldots \ldots$ & 0.6 & 0.6 & 1.0 & 0.6 & 0.6 & $\ldots$ \\
\hline Curvature in degrees ...... & 7.8 & 9.0 & 9.0 & 7.8 & 8.3 & 9.1 \\
\hline Sensitivity $\ldots \ldots \ldots \ldots \ldots$ & $\ldots$ & $\ldots$ & $\ldots$ & $\ldots$ & $\ldots$ & 2.36 \\
\hline Concentration of auxin & $\ldots$ & $\ldots$ & $\cdots$ & & & \\
\hline per $\mathrm{Kg} \ldots \ldots \ldots$ & 0.57 & 0.67 & 0.65 & 0.56 & 0.63 & $\ldots$ \\
\hline
\end{tabular}


pollination, but it is not conclusive. For this reason care was taken to use only unopened flower buds, so that there could be no possible question about the influence of pollination upon auxin content of the ovaries.

Usually about 200 large buds which were nearly ready to open were collected from each variety during the middle of the day. Within a few hours the ovaries had been removed from the buds, weighed, and placed in freshly distilled ether. The extraction time was usually two days, during which time the material was kept in an electric refrigerator. Table 1 is a composite of three such experiments.

Table 1 is a composite of several experiments, and it would be very difficult to include in it certain information which the reader might wish to know. Therefore the first experiment with lemons and oranges is given in detail in table 2 . It will be noticed that not all of the oranges were used in this experiment, but nevertheless has been chosen because it is the first one and is typical of the others.

In this experiment the differences between the seeded and the seedless varieties were not nearly so large as they were in the second experiment where the figures were as follows: seedless lemon 0.70 , seeded lemon 0.12 , Washington navel 1.05, Valencia 0.51, Rico No. 1 (seedless) 1.16, Paper rind (seeded) 0.45, and Satsuma (seedless) 4.01 gammas per kilogram fresh material.

Table 1 shows that in every instance the auxin content of the ovaries of the buds is higher in the parthenocarpic variety than in the corresponding seeded variety. On the other hand, after the ovaries have started to grow and the fruits are two or four weeks old, the auxin concentration has increased in the seeded varieties, while in the seedless varieties, where measured, it has decreased. Besides bringing out the fact that the auxin content is higher in the ovaries of the parthenocarpic varieties than in the non-parthenocarpic, the table also shows that fertilization and seed development increase the auxin concentration of the ovary. This increase is in agreement with the suggestion previously made that the seeds supply the auxin needed in the growth of the ovary into a fruit.

It should further be noticed that the Robertson Navel has a much higher auxin concentration than the Washington. This may be associated with the greater early growth rate of the former. When four weeks old the Robertson fruits are several times as large as the Washington, and they also mature considerably earlier. Both the seedless varieties of the Valencia have a much higher auxin content than the common seeded variety, and the Armstrong, which is known definitely to be a bud sport of the seeded Valencia, has an auxin concentration four times as large as that of its parent type. The Satsuma has a surprisingly large auxin content, but unfortunately there is nothing to compare it with except in a general way.
Diffusion experiments were also tried, but only the lemon gave any results. One millimeter thick 2 per cent agar sections were cut into blocks $8.0 \times$ $10.5 \mathrm{~mm}$., and these were subdivided into 12 equal pieces which were separated from one another on a moist slide. On top of each small block was placed an ovary, and the slide was then left in a damp Petri dish for two hours. The ovaries were removed from the agar blocks, which were placed on Avena coleoptiles in the usual way. It was found that the average curvature of 24 Avena coleoptiles treated with agar blocks upon which had rested the ovaries from the seedless varieties was $6.3 \pm 0.7^{\circ}$, while the average curvature of 24 other Avena coleoptiles treated with agar blocks upon which had rested ovaries from the seeded variety was only $3.3 \pm 0.6^{\circ}$. The actual concentration was not obtained in this experiment, but Went has found that the curvature of the Avena coleoptile is proportional to the auxin concentration in the agar block with which it was treated. Therefore there is a much greater auxin concentration in the ovaries of the seedless variety than in those of the seeded variety. This is in agreement with the data from the extraction experiment with lemons.

Three varieties of grapes, Thompson and Black Manukka seedless and seeded Muskat, were obtained from the Armstrong Nurseries. The exact relationship between these three varieties is not known, but it is thought by authorities to be fairly close.

Material was collected in the flower bud stage, and the whole flower buds were used in extraction. The procedure of extraction and testing was the same as that for the oranges. Table 3 gives the results for the one test that was made with flower buds.

Table 3. Auxin content in flower buds of three varieties of grapes. Auxin concentration is denoted in terms of indole acetic acid equivalents and the figures indicate gammas per kilogram of fresh material.

\begin{tabular}{ccc}
\hline \hline \multicolumn{2}{c}{ Seedless } & $\begin{array}{c}\text { Seeded } \\
\text { Muskat }\end{array}$ \\
\hline Thompson & Black Manukka & . \\
\hline 2.74 & 1.30 & 0.34 \\
\hline
\end{tabular}

The auxin content is much higher in the seedless varieties than in the seeded variety.

The three experiments with oranges extending over the whole blooming period, three experiments with lemons, one of which was a diffusion experiment, and one experiment with grapes all bring out the same fact-namely, that the ovaries of the varieties that are parthenocarpic have a much higher auxin concentration in the flower bud stage than those that develop into secded fruits.

Conclusion.-While it is true that only three species of plants that are naturally parthenocarpic 
have been investigated, yet the auxin content in the ovaries of all the parthenocarpic varieties is so much greater than in the non-parthenocarpic that there seems to be no question about this being a general condition. We can, therefore, at least tentatively or until contrary information is obtained in other species, accept the hypothesis that the reason some fruits develop without seeds is that they have a high anxin content in the ovaries at the time of blossoming and that this is high enough to set off the growth processes with the result that the ovary commences to grow even though there has been no fertilization. After growth has once commenced, it is continued either because auxin is produced in the ovary itself or because auxin is transported into it from the leaves.

\section{SUMMARY}

It has been shown that the auxin content in the ovaries of flower buds from varieties of oranges, lemons, and grapes that produce fruits parthenocarpically is higher than in the ovaries from corresponding varieties that do not produce fruits parthenocarpically.

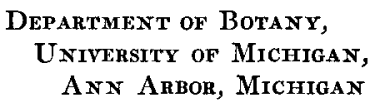

\section{LITERATURE CITED}

Dollfus, H. 1936. Wuchsstoffstudien. Planta 25: 1-21. Gardner, F. E., And P. C. Marth. 1937. Parthenocarpic fruits induced by spraying with growth promoting compounds. Bot. Gaz. 99: 184-195.

Gustafson, F. G. 1936. Inducement of fruit development by growth-promoting chemicals. Proc. Nat. Acad. Sci. 22: 628-636.

. 1937. Parthenocarpy induced by pollen extracts. Amer. Jour. Bot. 24: 10Q-107.

- 1938a. Further studies on artificial parthenocarpy. Amer. Jour. Bot. 25: 237-244.

. 1938b. Induced parthenocarpy. Bot. Gaz. 99: 840-844.
Hagemann, P. 1937. Über durch B-indolessigsäure ausgeläste parthenokarpie der Gladiole. Gartenbauwissenschaft. $11: 144-150$.

Lairach, F, 1932. Pollenhormone und Wuchsstoff. Ber. Deutsch. Bot. Ges. 50: 383-390.

Thimass, K. V. 1934. Studies on the growth hormone of plants. Jour. Gen. Physiol. 18: 23-34.

VAN Overneek, J. 1938. A simplified method for auxin extraction. Proc. Nat. Acad. Sci. 24: 42-46.

Went, F. W., and K. V. Thimann. 1937. Phytohormones. New York.

\section{A NEW TYPE OF EMBRYOGENY IN THE CONIFERS ${ }^{1}$}

\section{Phyllis L. Cook}

Having ReCentry completed a study of the early embryogeny of Juniperus communis, I believe that the results are worthy of publication in that they show a type of embryogeny hitherto unknown in the Conifers. Ottley (1909) studied the life history of $J$. communis through the first division of the zygote, and Noren (1907) and Nichols (1910) studied it through the development of the proembryo. Strasburger (1872) figured one embryo from $J$. communis as it appears during the first year and a single embryo from a mature seed from the same species. He also figured the proembryo and the developing multicellular embryo of $J$. virginiana. The process of development from the proembryo stage to the beginning of the multicellular stage is often long and complicated, and with the one exception of Strasburger's figure, no description of the process in any species of Juniperus has existed in the literature until the present. It is between the proembryo and the multicellular stages that the unique features occur.

During the last two summers, I have collected $J$. communis in the Muskoka Region of Ontario, where it is native, and on the campus of the University of Illinois, where it is cultivated. I have

1 Received for publication December 27, 1938.

To Dr. J. T. Buchholz I am indebted for direction and criticism of this study. had the privilege of studying mounted embryos of $J$. communis collected at Cold Spring Harbor, Long Island, by Dr. J. T. Buchholz, and of $J$. mexicana from Austin, Texas, also collected by Dr. Buchholz. For the study of fertilization, the proembryo, and the late embryo stages, I have used microtome sections, and for the rest of the embryogeny I have employed the Buchholz (1938) method of mounting whole conifer embryo complexes.

Investigations.-In Illinois fertilization takes place during the first or the second week in June, and in Ontario during the last week in June. One, two, three, or occasionally more eggs in each archegonial complex are fertilized. Nichols (1910) states that normally eight free nuclei are present before the proembryo becomes cellular, and my findings agree with his. The complete proembryo consists of about twelve cells arranged in three more or less definite tiers. The nuclei of the upper tier are never completely walled in, and they take no part in further development; the cells of the middle tier elongate, pushing the cells of the lowest tier out of the archegonium into the nutritive tissue of the gametophyte. In the cavity which they form in the gametophyte, the cells which constituted the two lower tiers of the proembryo begin a process of development which is unique in the Coniferales and 